${ }^{1}$ Forget, B. G., and Weissman, S. M., J. Biol. Chem., 244, 3148 (1969).

2 Forget, B. G., and Jordan, B., Science, 167, 382 (1970).

3 Williamson, R., and Brownlee, G., FEBS Lett., 3, 306 (1969).

4 Rosset, R., Monier, R., and Julian, J., Bull. Soc. Chim. Biol., 46, 87 (1964).

5 Galibert, F., Larsen, C. L., Lelong, J. C., and Boiron, M., Nature, 207, 1039 (1965).

6 Brown, D. D., and Littna, E., J. Mol. Biol., 29, 95 (1966).

7 Knight, E., and Darnell, J. E., J. Mol. Biol., 28, 491 (1967).

Sarkar, N., and Comb, D. G., J. Mol. Biol., 39, 31 (1969).

9 Nomura, M., and Erdmann, V. A., Nature, 228, 744 (1970).

10 Warner, J. R., and Soeiro, H. C., Proc. US Nat. Acad. Sci., 58, 1984 (1967).

11 Brown, D. D., and Weber, C. S., J. Mol. Biol., 34, 661 (1968).

12 Brown, D. D., and Dawid, I., Science, 160, 272 (1968).

${ }^{13}$ Loening, U. E., Jones, K., and Birnstiel, M. L., J. Mol. Biol., 45, 353 (1969).

14 Sanger, F., Brownlee, G. G., and Barrell, B. G., J. Mol. Biol., 13, 373 (1965).

15 Thomas, C., Arch. Biol. (Liège), 78, 347 (1967).

16 Gall, J. G., Proc. US Nat. Acad. Sci., 60, 553 (1968).

17 Miller, jun., O. L., and Beatty, B. R., Science, 164, 955 (1969).

18 Kirby, K. S., Biochem. J., 96, 266 (1965).

19 Reynier, M., Aubert, M., and Monier, R., Bull. Soc. Chim. Biol., 49, 1205 (1967).

20 Brownlee, G. G., and Sanger, F., J. Mol. Biol., 23, 337 (1967).

\section{Lead Absorption from the Intestine in Newborn Rats}

THE tendency of the young of a given species to be more prone to lead poisoning than the adult has been observed by several authors 1 , and we have investigated whether one of the reasons for this could be an increased absorption of lead from the intestine during an early stage of life.

We used 5-7 day old rats which were artificially fed for $8 \mathrm{~h}$ with cow's milk to which $\mathrm{CaCl}_{2}$ and $\mathrm{KH}_{2} \mathrm{PO}_{4}$ were added to adjust the calcium and phosphate content to the normal level of rat's milk ${ }^{2}$. The technique was essentially that used before ${ }^{3,4}$. Carrier-free lead-203 was added to the milk and each animal received about $2 \mu \mathrm{Ci}$. At the end of the artificial feeding period the young were returned to their mothers where they stayed until they were killed 40 and $80 \mathrm{~h}$ after the beginning of the experiments. The radioactivity of lead-203 was determined in the whole body before and after removal of the gastrointestinal tract in a two sodium iodine crystal assembly. Retention was expressed as percentage of the ingested dose.

Table 1 reveals a high retention of about $55 \%$ of lead-203 at both intervals. The lower value in the carcass at $40 \mathrm{~h}$ indicates that some radioactive lead was still present in the gastrointestinal tract at the earlier time interval. This fraction becomes absorbed after $80 \mathrm{~h}$, as indicated by the higher value in the carcass and by the same retention figure obtained in the whole body and carcass at the later interval.

Table 1 Absorption of Radioactive Lead from the Intestine in Artificially Fed 5-7 Day Old Rats

\begin{tabular}{cccc} 
& & \multicolumn{2}{c}{$\begin{array}{c}\text { Lead-203 in the body } \\
\% \text { ingested dose }\end{array}$} \\
No. of rats & $\begin{array}{c}\text { Time of } \\
\text { death (h) }\end{array}$ & $\begin{array}{c}\text { With intestinal } \\
\text { tract }\end{array}$ & $\begin{array}{c}\text { Without intestinal } \\
\text { tract }\end{array}$ \\
12 & 40 & $55.80 \pm 2.3$ & $41.86 \pm 1.85$ \\
17 & 80 & $57.41 \pm 1.71$ & $53.37 \pm 1.77$ \\
\hline
\end{tabular}

Lead-203, $\mathrm{CaCl}_{2}$ and $\mathrm{KH}_{2} \mathrm{PO}_{4}$ were added to cow's milk which was fed to rats by means of a dropper during $8 \mathrm{~h}$; each rat received an average of seventeen drops $(0.45 \mathrm{ml}$.); each figure represents the arithmetic means and the standard error of the mean.

The principal finding, however, remains the very high absorption of lead from the intestine of newborn rats. Adult rats (4 month old females) retain within the same time interval only about $1 \%$ of the oral dose of radioactive lead ${ }^{5}$. If we compare these results with those obtained in our previous experiments on absorption of calcium and strontium in newborn rats with almost the same experimental technique ( $70-75 \%$ absorption for ${ }^{47} \mathrm{Ca}$ and ${ }^{85} \mathrm{Sr}$ after $40 \mathrm{~h}$ ), it is seen that the absorption of lead is only $25 \%$ lower than the very high absorption of calcium and strontium characteristic for this age group. If we assume that the percentage of intestinal lead absorption is not influenced by dose ${ }^{6}$, we could expect much more lead to be absorbed from the intestine in the young than generally supposed. If these values are expressed per kilogram body weight, the difference in the amount of lead absorbed per unit weight in young and adults would be even greater. We therefore consider that this factor should be taken into consideration when interpreting the well known differences in the symptoms of lead poisoning in adults and young children. Our results could also be important for determining criteria for human safety from contamination of the ambient atmosphere with lead, which might have to be corrected for young children when compared with adult values.

This work was supported by a research grant from the US Environmental Protection Agency.

KRISTA Kostial

I. ŠIMONOVIĆ Marica Pisonić

Institute for Medical Research, Zagreb

Received April 16; revised July 19, 1971.

1 Barltrop, D., Postgrad. Med. J., 45, 129 (1969).

2 Spray, C. M., Brit. J. Nutrit., 4, 354 (1950).

${ }^{3}$ Kostial, K., Simonović, I., and Pišonić, M., Nature, 215, 1181 (1967).

- Kostial, K., Duraković, A., Simonović, I., and Juvančić, V., Intern. J. Radiat. Biol., 15, 563 (1969).

${ }^{5}$ Kello, D., and Kostial, K., Summaries, 3, Yugoslav Congress of Industrial Medicine (1971), Arh. Hig. Rada. Suppl. (in the press).

- Blaxter, K. L., J. Comp. Pathol., 60, 140 (1950).

\section{Spanish Moss, a Sensor for Lead}

THE heavy metal content of various plants has been related to sources of air pollution ${ }^{1}$. Trees growing near London, England, were found to contain more lead than those growing in the country ${ }^{2}$. Grass near a highway was found to contain more lead than grass further away ${ }^{3}$. These studies involved root type plants that obtain their nourishment from the soil.

More useful information can be obtained from measurements of heavy metals in epiphytes, which derive all their nutrients from the air. They may concentrate certain elements in a manner analogous to the concentration of mercury in tuna fish and DDT in penguins. Ruhling and Tyler reported that some mosses are good indicators for lead accumulation ${ }^{4}$. Tyler has shown that carpet-forming mosses may also be used to measure the deposition of other heavy metals (unpublished results of $\mathrm{G}$. Tyler).

We wish to report some preliminary measurements made with Spanish moss (Tillandsia usneoides), an epiphyte and a member of the family Bromiliaceae, which promises to prove useful as a monitor of lead and other heavy metals in the atmosphere. Wherry and Buchanan analysed three samples of the ash of Spanish moss and found them to contain much soda, potash, ferric oxide, sulphur, chlorine, and silica ${ }^{5}$. They found a sample from the sea coast contained more chlorine than an inland sample, suggesting a higher level of atmospheric salt near the coast due to sea spray. They considered that the scales which cover the moss hold capillary water from which the plant absorbs nutrients. They found little systematic difference between washed and unwashed samples indicating that adherent dust had a negligible effect on their results. Wherry and Capen reported additional measurements of Spanish moss and Ball-moss (Tillandsia recurvata L.) ${ }^{6}$. 